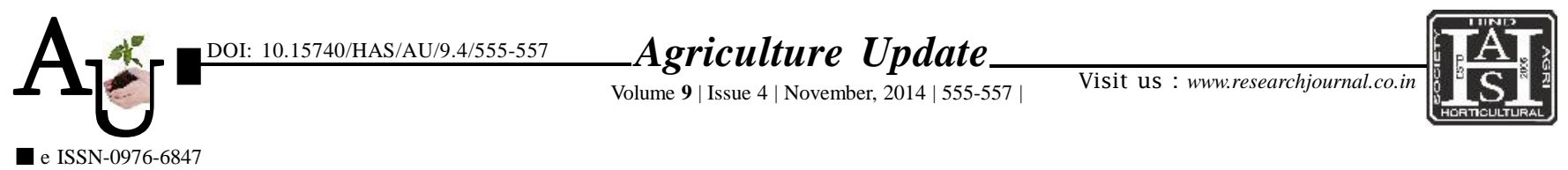

\title{
Research Article Technological needs perceived by farm women in sorghum production
}

AMTUL WARIS

Article Chronicle : Received : 23.07.2014;

Revised :

07.10.2014;

Accepted :

18.10.2014

\section{KEY WORDS :}

Farm women,

Technological needs, Need based technology reduce physical fatigue.
SUMMARY : Farm women in our country have limited access to technological advice, as extension programmes tend often to transfer agricultural technical information to men and focus on home technology for women. In the process only male farmers are linked to the agricultural scientists ignoring the importance for the need for knowledge and experience of women in technology design, development and evaluation. The present study, therefore, envisaged to identify the technological needs of farm women in sorghum production to develop need based technologies. The study was conducted in semi-arid region of Andhra Pradesh. Data were collected from 256 farm women from 8 villages. Technological needs were defined as technologies which the farm women require to carry out the various farming activities in the most efficient manner without any strain on their part. Technological needs were identified using the rank based quotient (RBQ) method. The farm women perceived the following technological needs for sorghum production activities. A simple device to sow seeds, as sowing is a skillful and tiring activity, low cost easily operable winnowers that reduce physical fatigue, possibility of altering the harvesting time as it is very sunny and high stalks of sorghum cause suffocation, mechanism that protects from dust during winnowing as it causes soreness in the mouth, modify/redesign sickles to prevent minor injuries, improvising the ("gorru") seed drill as hands were hurt while pouring the seeds and mechanical weeders that

How to cite this article : Waris, Amtul (2014). Technological needs perceived by farm women in sorghum production. Agric. Update, 9(4): 555-557.

\section{AMTUL WARIS}

Directorate of Rice Research, HYDERABAD

(A.P.) INDIA

Email: amtul.waris@ gmail.com 